\title{
Relationship between field resistance to Phytophthora ramorum and constitutive phenolic chemistry of coast live oak
}

\author{
By A. M. Nagle ${ }^{1}$, B. A. Mcpherson ${ }^{2}$, D. L. Wood ${ }^{2}$, M. Garbelotto ${ }^{2}$ and \\ P. BONELLO ${ }^{1,3}$
}

\begin{abstract}
${ }^{1}$ Department of Plant Pathology, The Ohio State University, 201 Kottman Hall, 2021 Coffey Rd. Columbus, OH 43210, USA; ${ }^{2}$ Department of Environmental Science, Policy, \& Management, University of California, Berkeley, CA, USA; ${ }^{3}$ E-mail: bonello.2@osu.edu (for correspondence)
\end{abstract}

\section{Summary}

Sudden oak death, caused by Phytophthora ramorum, has resulted in high levels of coast live oak (CLO) mortality. However, some CLO survive in areas with high disease pressure and may thus be resistant. We tested the hypothesis that such field-resistant trees contain constitutively higher levels of phenolics than susceptible trees. Phloem was sampled from the trunks of two groups of trees (one previously inoculated, one naturally infected with $P$. ramorum) categorized over the course of several years as putatively resistant (PR, no symptoms), in remission (IR, showed symptoms but then recovered) and symptomatic (S). Individual and total soluble phenolics from these trees were quantified. There were no significant differences in individual or total soluble phenolics between groups of naturally infected trees. However, inoculated PR and IR trees were characterized by higher constitutive levels of ellagic acid, a tyrosol derivative, and an unidentified phenolic than $\mathrm{S}$ trees. Ellagic acid and tyrosol-like compounds in CLO phloem are promising resistance biomarker candidates.

\section{Introduction}

Since its identification as the causal agent of sudden oak death (SOD) (Rizzo et al. 2002), Phytophthora ramorum has killed tens of thousands of coast live oak (CLO) (Quercus agrifolia Nee), California black oak (Q. kelloggii Newberry) and tanoak trees (Lithocarpus densiflorus [Hook. \& Arn.] Rehder) and threatens to dramatically change the composition of California's mixed-evergreen and redwood forests (Brown and Allen-Diaz 2009).

Phytophthora ramorum is an oomycete (kingdom Straminopila) plant pathogen that infects a variety of woody ornamental species in nursery settings throughout Europe and the United States and native forest species in northern and central coastal California, southern Oregon and England. In oaks, the pathogen infects and kills phloem tissue in stems and boles, causing bleeding cankers visible on intact bark (Rizzo et al. 2002; Rizzo and Garbelotto 2003; Parke et al. 2004; Hansen et al. 2005; McPherson et al. 2005, 2010).

Projected mortality by 2014 in CA mixed-evergreen forests heavily infested with $P$. ramorum is $59-70 \%$ of CLO basal area, assuming the absence of host resistance in infected trees (Brown and Allen-Diaz 2009). However, there is evidence that resistance may be present in CLO. Dodd et al. (2005) conducted a greenhouse assay in which several cut branches from each experimental tree were inoculated with $P$. ramorum over four trial dates and showed up to eightfold variation in mean lesion size between trees. Their conclusion that remnant, resistant individuals may survive in infested forests seems consistent with ongoing long-term field studies in areas where P. ramorum has been established for many years. The persistence of asymptomatic CLOs in heavily, naturally infested disease 
progression plots established in 2000 has been reported (McPherson et al. 2005, 2010). Approximately one-third of CLOs in a population directly inoculated with the pathogen in the field failed to develop symptoms or appeared to recover following initial symptom development (McPherson, unpublished data). Asymptomatic trees are usually found in close proximity to symptomatic individuals as well as infected bay laurel, the main source of sporangia in these areas (Davidson et al. 2005). Given these observations, we hypothesize that the persistence of many asymptomatic trees is unlikely to be due to disease escape and may be an expression of field resistance. An alternative explanation is provided by Dodd et al. (2008), who proposed that a lack of synchronicity in pathogen and host phenology may make certain CLOs less likely to become infected with $P$. ramorum, but their study did not examine mechanisms of apparent long-term survival of infected individuals, which was the main goal of this study. In fact, there has been only one previous study examining the correlates of possible host resistance in CLO (Ockels et al. 2007).

The role of certain phenolics (both constitutive and induced) in tree defence strategies is well documented, particularly in conifers (Brignolas et al. 1998; Schultz and Nicholas 2000; Bonello and Blodgett 2003; Lieutier et al. 2003; Venalainen et al. 2003; Wallis et al. 2008), but also in a few angiospermous species (Bucciarelli et al. 1999; Hakulinen et al. 1999; Hakulinen and Julkunen-Tiitto 2000; Ruuhola et al. 2007; Witzell and Martin 2008). However, few studies have dealt with the defensive role of phenolics against pathogens in stem tissues of oaks. Ockels et al. (2007) demonstrated elevated levels of gallic acid and ellagic acid in CLO phloem infected with $P$. ramorum relative to healthy phloem in two of three trials. In one of the three trials, tyrosol and ellagic acid were elevated in infected phloem. Tyrosol and gallic acid were also shown to have strong, dose-dependent, inhibitory effects in vitro on four species of Phytophthora. Taken together, these results suggest that phenolic compounds may be important in induced defence responses against $P$. ramorum, but constitutive phenolic levels in phloem tissues may also play a role in resistance to initial infection.

Our long-term goal is to identify easily screenable biomarkers of resistance, i.e. compounds present in consistently higher levels in more resistant plants that could be used to identify resistant trees. To be easily employable, biomarkers should be associated with the uninfected state of a plant. Therefore, while inducible biomarkers may have a role in the overall assessment of a host plant predisposition to resist pathogenic attack, here we assessed the potential significance of individual phenolics in CLO resistance by studying associations between their constitutive phloem concentrations and trunk symptoms caused by $P$. ramorum.

\section{Materials and methods}

To compare levels of phenolics in groups of trees differing in resistance to the pathogen, we sampled trunk phloem in October and December 2008. The China Camp (CC) population, which has been observed repeatedly since 2000, is located in Marin County, California, in a natural infection centre and represents remnant trees in an area with extensive mortality (representative coordinates: $38^{\circ} 00^{\prime} 6^{\prime \prime} \mathrm{N}, 122^{\circ} 29^{\prime} 13^{\prime \prime} \mathrm{W}$ ). The second population (Nike) (representative coordinates: $37^{\circ} 59^{\prime} 45.1^{\prime \prime} \mathrm{N}, 122^{\circ} 30^{\prime} 2.2^{\prime \prime} \mathrm{W}$ ) is also located in Marin County, California, within stands with elevated infection levels and is contiguous with the same forested watershed as the CC population. The Nike site was subjected to artificial inoculation trials in 2002 and has been under close observation since (McPherson et al. 2008). Briefly, trees had been inoculated by removing a 2-cm diameter bark plug from trunks with a hole cutter approximately $1.5 \mathrm{~m}$ from the soil line and inserting a $5.5 \mathrm{~mm}$ agar plug of $P$. ramorum isolate Pr52 (originally collected by D. Rizzo, grown on $10 \%$ V8 agar for 3 weeks) against the cambium. Isolate Pr52 has been used repeatedly by us and D. Rizzo and has maintained its aggressiveness in the course of several years. Bark plugs were 
replaced, and wounds were covered with aluminium foil and held in place with tape to minimize desiccation and contamination (Rizzo et al. 2002; McPherson et al. 2008).

Since March 2000, the CC study area has exhibited infections in 26-38\% (interannual variation) of the living CLOs ( $\mathrm{n}=401$ living trees in 2000) (McPherson et al. 2010). During this period, $29.9 \%$ of the CLOs died with SOD symptoms. Of 80 CLO asymptomatic in 2002 in the Nike site, 40 were inoculated with $P$. ramorum, 20 were mock inoculated and 20 were left unmanipulated. Trees included in our study have been monitored closely since inoculation, and only inoculated trees were sampled at this site. Twenty-eight percent of inoculated trees never developed bleeding and $40 \%$ exhibited bleeding within 9 months of inoculation, but subsequently became asymptomatic. At the time of sampling in December 2008, 90\% of the inoculated trees were still alive, with $78 \%$ displaying signs of active defence responses to infection (i.e. growth of callus tissue and canker healing). Mock inoculations did not produce any detectible lesions or SOD symptoms (McPherson et al. 2008). Therefore, we are confident that the apparent resistance seen in some Nike trees is not simply the result of inoculation failure. Remnant CLOs in the two post-epidemic stands were categorized based upon symptoms:

1.PR (Putatively resistant): asymptomatic trees that never showed symptoms of infection with $P$. ramorum.

2.IR (In remission): trees that showed bleeding symptoms at one time, but are currently asymptomatic, i.e. trees that have putatively healed and are considered intermediately resistant.

3.S (Symptomatic): trees that are currently showing symptoms of infection.

For the purpose of identifying field-resistant CLOs, we consider both PR and IR trees resistant, because these trees either resisted infection before symptoms could develop or appear to have healed. (As noted previously, disease escape is highly unlikely.) Trees were categorized in terms of symptomatology into three separate groups and relevant a priori comparisons are therefore between $\mathrm{PR} / \mathrm{IR}$ trees and $\mathrm{S}$ trees.

There were 27 trees included in the CC study $(P R, n=9 ; I R, n=9 ; S, n=9)$ and 36 trees included in the Nike study ( $P R, n=11 ; I R, n=15 ; S, n=10)$. Two phloem samples were obtained from each tree. On trees with current or previous infections, samples were taken at least $30 \mathrm{~cm}$ away from the margins of lesions. A previous study (Ockels et al. 2007) showed that phloem sampled away from lesions was chemically indistinguishable from phloem taken from healthy trees. Thus, healthy phloem from infected trees was assumed to contain constitutive levels of phenolics. The outer (cork) bark over each sampling site was removed with a chisel. Phloem shavings were removed using a cordless drill with a $1.9 \mathrm{~cm}$ auger drill bit. The phloem samples were collected directly into sterile, $50 \mathrm{ml}$ plastic centrifuge tubes and placed in a cooler with dry ice. After arrival in the laboratory, phloem samples were stored on dry ice until extraction in methanol as described in the following.

\subsection{Chemical analyses}

Phloem samples harvested from experimental trees were finely ground in liquid $\mathrm{N}$ and $0.1 \mathrm{~g}$ fresh weight $(\mathrm{FW})$ were extracted twice with $0.5 \mathrm{ml} \mathrm{HPLC}$ grade methanol at $-20^{\circ} \mathrm{C}$ for $24 \mathrm{~h}$ as described previously (Ockels et al. 2007). Pooled extracts were stored at $-20^{\circ} \mathrm{C}$ and centrifuged $(5 \mathrm{~min}$ at $13000 \mathrm{~g}$ ) prior to analysis to remove particulate matter. Extracts were analysed with a Waters 2690 Separations Module while keeping them at $4^{\circ} \mathrm{C}$ in an autosampler; $10 \mu \mathrm{l}$ injections were made onto a Waters XTerra RP18, $5 \mu \mathrm{m}, 4.6 \times 150 \mathrm{~mm}$ column, maintained at $30^{\circ} \mathrm{C}$. Samples were separated using a water (A) - methanol (B) solvent gradient acidified with $2 \%$ acetic acid. The solvent gradient was as follows (percentages refer to proportion of solvent B): $0 \%$ ( $0-2 \mathrm{~min}) ; 0-10 \%(2-4 \mathrm{~min}) ; 10-48 \%$ (4-20 min); 48-100\% (20-38 min); 100\% (38-39 min). Solvent flow rate was $1.0 \mathrm{ml} / \mathrm{min}$ 
for the first $20 \mathrm{~min}$, then increased to $1.75 \mathrm{ml} / \mathrm{min}$ from 20-39 min. A Waters 996 Photo Diode Array (PDA) detector scanning between 237 and $400 \mathrm{~nm}$ was used to detect soluble phenolics (Bonello and Blodgett 2003). Detector channel $280 \mathrm{~nm}$, which is widely used for detection of phenolic compounds, was used for data processing and analysis of all samples. Additionally, detector channel $370 \mathrm{~nm}$ was used to provide better resolution for certain compounds, such as ellagic acid, which are frequently obscured by the large tannin hump present in chromatograms generated at $280 \mathrm{~nm}$.

Peaks were identified and quantified using published methods (Ockels et al. 2007). Unknown peaks were named by their retention time, e.g. a peak eluting at 4.5 min was called peak 4.5. The sums of all peak areas, calculated separately using the 280 and $370 \mathrm{~nm}$ channels, were taken to represent total soluble phenolics (Bonello and Blodgett 2003; Blodgett et al. 2005) for both populations of CLO.

\subsection{Statistical analyses}

Data were initially analysed by univariate Anova. Levene's test was used to examine homogeneity of variance in datasets for each phenolic compound and for total soluble phenolics, and datasets were square root or ln-transformed to satisfy the assumptions of ANOvA. In cases where homogeneity of variance could not be achieved, the Kruskal-Wallis test was used. A priori comparisons between field-resistant and susceptible trees were conducted by pooling data for PR and IR trees and comparing those data to $\mathrm{S}$ trees.

Nike and CC were analysed separately because of the difference in challenge history. In the Nike study, effect of category (PR, IR and S) was tested with multivariate ANOvA on ln-transformed data. Comparisons between categories for individual phenolics were made using the LSD test. Effect of category in CC was tested using Kruskal-Wallis tests because error variances could not be normalized with transformation in this dataset.

\section{Results}

To compare phenolic concentrations between PR, IR and S groups, we analysed 19 major peaks, nine at $280 \mathrm{~nm}$ and 10 at $370 \mathrm{~nm}$, as well as total peak areas at 280 and $370 \mathrm{~nm}$. We were able to reliably identify only three of the peaks (Ockels et al. 2007): a tyrosol derivative (which we called tyrosol derivative 2), catechin and ellagic acid. Overall patterns of phenolic concentrations differed between Nike and CC populations:

\subsection{Nike cohort}

Significant variation between PR, IR and/or $\mathrm{S}$ tree phenolic concentrations was found for tyrosol derivative 2 and ellagic acid (Table 1, Fig. 1). An a priori contrast between resistant

Table 1. Mean concentrations $( \pm \mathrm{SE})$ of tyrosol derivative 2 and ellagic acid in the three resistance categories (PR: putatively resistant; IR: in remission; S: symptomatic) of coast live oak trees at the Nike site.

\begin{tabular}{|lccc|}
\hline & \multicolumn{3}{|c|}{ Mean concentration (mg/g FW) } \\
\cline { 2 - 4 } & $\mathrm{PR}$ & $\mathrm{IR}$ & $\mathrm{S}$ \\
\hline Tyrosol derivative $2^{1}$ & $9.27 \pm 1.00 \mathrm{a}^{2}$ & $8.97 \pm 0.89 \mathrm{a}$ & $6.29 \pm 0.64 \mathrm{~b}$ \\
Ellagic acid & $0.29 \pm 0.06 \mathrm{ab}$ & $0.32 \pm 0.02 \mathrm{a}$ & $0.18 \pm 0.05 \mathrm{~b}$ \\
${ }^{1}$ Concentrations given in tyrosol equivalents. & & \\
${ }^{2}$ Letters indicate significant differences within rows at $\alpha=0.05$. & \\
\hline
\end{tabular}



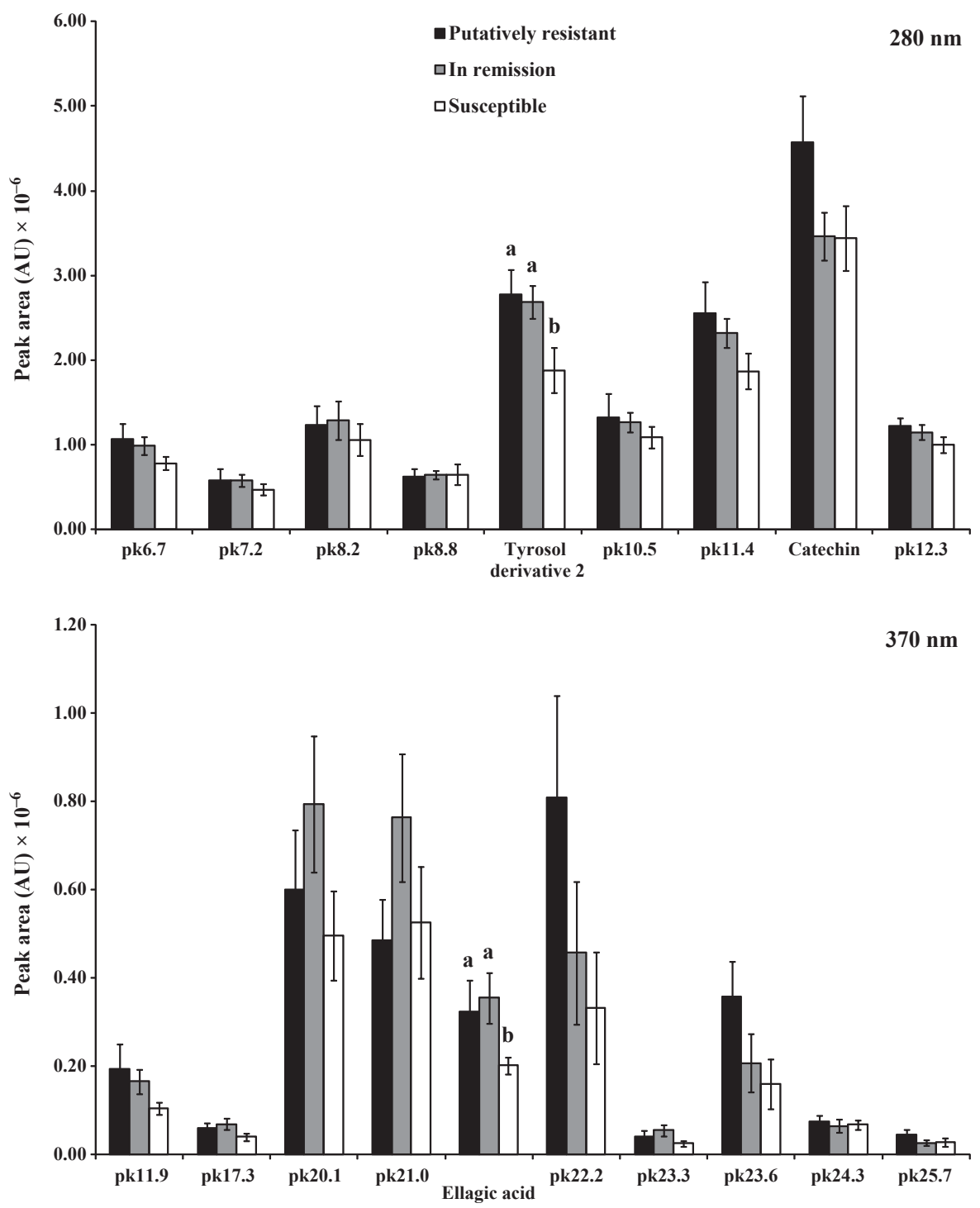

Fig. 1. Peak areas for individual phenolic compounds in coast live oak trees at the Nike site at $280 \mathrm{~nm}$ and $370 \mathrm{~nm}$. (AU = absorbance units) With the exception of tyrosol derivative 2 (detected at $280 \mathrm{~nm}$ ) and ellagic acid (detected at $370 \mathrm{~nm}$ ) (see Table 1 for actual concentrations), there were no statistically significant differences at $\alpha=0.05$ among PR, IR and S trees (PR: putatively resistant; IR: in remission; $\mathrm{S}$ : symptomatic) for each individual compound (LSD test).

trees (PR and IR combined) and $\mathrm{S}$ trees showed significant differences for three compounds: tyrosol derivative $2\left(\chi^{2}=7.205, \mathrm{p}<0.01\right)$, ellagic acid $\left(\chi^{2}=5.434, \mathrm{p}<0.05\right)$ and peak $11.4\left(\chi^{2}=4.053, \mathrm{p}<0.05\right)$ (approximately 30,40 and $20 \%$ higher in resistant relative to susceptible trees, respectively). Total soluble phenolics did not differ among PR, IR and S trees at $280 \mathrm{~nm}$ (data not shown) or $370 \mathrm{~nm}$ (Fig. 2). However, resistant trees (PR 


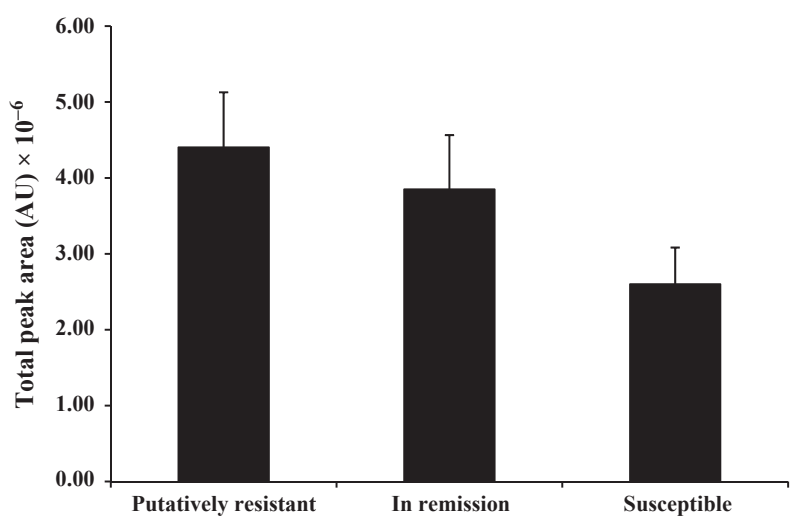

Fig. 2. Total soluble phenolics measured as the sum of all peak areas at $370 \mathrm{~nm}$ for coast live oak trees at the Nike site. (AU = absorbance units.) While PR, IR and S trees (PR: putatively resistant; IR: in remission; S: symptomatic) did not differ significantly among each other, a contrast between resistant (PR and IR combined) and $\mathrm{S}$ trees showed that the former contained significantly more total soluble phenolics (Kruskal-Wallis test: $\chi^{2}=4.795, \mathrm{p}<0.05$ )

and IR combined) contained $57 \%$ more metabolites by peak area $(\mathrm{p}<0.05)$ than susceptible trees at $370 \mathrm{~nm}$ (Fig. 2).

\subsection{CC cohort}

There were no significant differences between PR, IR and S trees for any individual compounds or for total soluble phenolics.

\section{Discussion}

There was no significant overall effect of tree status (PR, IR or S) on the concentration of individual phenolics in either the CC or Nike cohorts. However, in Nike CLOs, the constitutive concentration of total soluble phenolics (measured as total peak area of chromatograms at $370 \mathrm{~nm}$ ) and certain, perhaps critical, individual phenolics (Table 1) was higher in resistant (i.e. PR and IR) trees. Biochemical activity of ellagic acid against $P$. ramorum has not been established because of difficulty in solubilizing this compound for our laboratory bioassays (Ockels et al. 2007). However, ellagic acid and its derivatives are known to have antimicrobial activity (e.g. Zhou et al. 2007); furthermore, they are known to accumulate in high amounts in CLO phloem infected with $P$. ramorum (up to $1.47 \pm 0.69 \mathrm{mg} / \mathrm{g} \mathrm{FW}$ in artificially inoculated trees) (Ockels et al. 2007).

Chemical characterization of the tyrosol derivatives in our extracts will be necessary before activity can be postulated, but our prior experiments suggest this suite of phenolics may play an important defensive role in CLO. Ockels et al. (2007) showed that tyrosol was induced in CLO phloem infected with $P$. ramorum relative to non-cankered phloem from the same trees. The same study also described a strong, dose-dependent inhibitory effect of tyrosol on in vitro growth of several Phytophthora species, including P. ramorum. The highest in vitro concentration tested in the study by Ockels et al. (2007), $6.0 \mathrm{mg} / \mathrm{ml}(1 \mathrm{ml}$ media was assumed equivalent to $1 \mathrm{~g} \mathrm{FW}$ phloem), produced nearly complete inhibition of growth of all four Phytophthora spp. tested. The mean concentration of tyrosol derivative 2 in PR and IR CLO phloem (in tyrosol equivalents) was approximately $9 \mathrm{mg} / \mathrm{g} \mathrm{FW}$ in our 
study. Antifungal activity of tyrosol has also been described elsewhere (Slininger et al. 2004; Baidez et al. 2006).

It remains unclear why patterns differed between the two sites. One reason for this discrepancy may be that categorizing CLO into PR, IR and S trees is not always straightforward. For example, trees in any of the three categories at the CC site may have been attacked at different times over a few years, making assessment of their condition a little more observer-dependent. In contrast, the fact that trees in the Nike group were directly challenged with $P$. ramorum on a single inoculation date may make disease development comparisons and tree categorization more consistent than in CC.

Seasonal variation in phenolic chemistry has been well characterized in foliage of various tree species, including oaks (Hatano et al. 1986; Salminen et al. 2004; Yarnes et al. 2008) and has been observed in phloem tissue of CLO as well (Ockels et al. 2007). Given seasonal variation of phenolic levels as well as the variability observed in our study, future studies of this nature may benefit from conducting replicate trials in the same season. Elucidating differences in phenolic chemistry in these three categories may be especially relevant in the spring, when the pathogen is apparently most active (Rizzo et al. 2005), rather than fall as in our study.

Another major obstacle to future studies of this kind is our inability to identify, postepidemic, trees that are truly resistant and susceptible to $P$. ramorum. The fact that we are unable to obtain representative samples of the most susceptible CLOs prior to their infection and death makes post-epidemic comparisons of chemical defences between resistant and susceptible trees problematic. This issue can only be resolved by banking information on constitutive phenolics from large numbers of trees prior to infestation, with comparisons made following death of the most susceptible trees. A study is now in progress to address this issue.

In spite of these limitations, it does appear that the production of tyrosol-like compounds is constitutively upregulated in the more resistant CLOs examined. Taken together, significantly higher levels of total soluble phenolics, ellagic acid and a tyrosol derivative observed in the resistant (PR and IR) Nike trees, the documented antimicrobial activity of ellagic acid derivatives (e.g. Zhou et al. 2007) and the strong in vitro anti-Phytophthora activity of tyrosol (Ockels et al. 2007) suggest that these compounds may be especially good candidates for further examination as potential biomarkers for resistance of CLO to $P$. ramorum. Data from spring time may be especially ecologically relevant, given that this is when infection appears to take place in coastal California forests (Rizzo et al. 2005).

\section{Acknowledgements}

Funding was provided by USDA Forest Service Research Joint Venture Agreement \#07-JV-11242300075 and state funds appropriated to the Dept. of Plant Pathology, The Ohio State University. Technical and statistical analysis assistance at OSU was kindly provided by Duan Wang, Nathan Kleczewski, Justin Whitehill and Shannon Quinn.

\section{References}

Baidez, A. G.; Gomez, P.; Del Rio, J. A.; Ortuno, A., 2006: Antifungal capacity of major phenolic compounds of Olea europaea L. against Phytophthora megasperma Drechsler and Cylindrocarpon destructans (Zinssm.) Scholten. Physiol. Mol. Plant Pathol. 69, 224-229.

Blodgett, J. T.; Herms, D. A.; Bonello, P., 2005: Effects of fertilization on red pine defense chemistry and resistance to Sphaeropsis sapinea. For. Ecol. Manag. 208, 373-382.

Bonello, P.; Blodgett, J. T., 2003: Pinus nigra-Sphaeropsis sapinea as a model pathosystem to investigate local and systemic effects of fungal infection of pines. Physiol. Mol. Plant Pathol. 63, 249-261.

Brignolas, F.; Lieutier, F.; Sauvard, D.; Christiansen, E.; Berryman, A. A., 1998: Phenolic predictors for Norway spruce resistance to the bark beetle Ips typographus (Coleoptera : Scolytidae) and an associated fungus, Ceratocystis polonica. Can. J. For. Res. 28, 720-728. 
Brown, L. B.; Allen-Diaz, B., 2009: Forest stand dynamics and sudden oak death: Mortality in mixedevergreen forests dominated by coast live oak. For. Ecol. Manag. 257, 1271-1280.

Bucciarelli, B.; Ostry, M. E.; Fulcher, R. G.; Anderson, N. A.; Vance, C. P., 1999: Histochemical and microspectrophotometric analyses of early wound responses of resistant and susceptible Populus tremuloides inoculated with Entoleuca mammata (Hypoxylon mammatum). Can. J. Bot. 77, 548-555.

Davidson, J. M.; Wickland, A. C.; Patterson, H. A.; Falk, K. R.; Rizzo, D. M., 2005: Transmission of Phytophthora ramorum in mixed-evergreen forest in California. Phytopathology 95, 587-596.

Dodd, R. S.; Huberli, D.; Douhovnikoff, V.; Harnik, T. Y.; Afzal-Rafii, Z.; Garbelotto, M., 2005: Is variation in susceptibility to Phytophthora ramorum correlated with population genetic structure in coast live oak (Quercus agrifolia)? New Phytol. 165, 203-214.

Dodd, R. S.; Huberli, D.; Mayer, W.; Harnik, T. Y.; Afzal-Rafii, Z.; Garbelotto, M., 2008: Evidence for the role of synchronicity between host phenology and pathogen activity in the distribution of sudden oak death canker disease. New Phytol. 179, 505-514.

Hakulinen, J.; Julkunen-Tiitto, R., 2000: Variation in leaf phenolics of field-cultivated willow (Salix myrsinifolia) clones in relation to occurrence of Melampsora rust. For. Pathol. 30, $29-41$.

Hakulinen, J.; Sorjonen, S.; Julkunen-Tiitto, R., 1999: Leaf phenolics of three willow clones differing in resistance to Melampsora rust infection. Physiol. Plant. 105, 662-669.

Hansen, E. M.; Parke, J. L.; Sutton, W., 2005: Susceptibility of Oregon forest trees and shrubs to Phytophthora ramorum: A comparison of artificial inoculation and natural infection. Plant Dis. 89, 63-70.

Hatano, T.; Kira, R.; Yoshizaki, M.; Okuda, T., 1986: Seasonal changes in the tannins of Liquidambar formosana reflecting their biogenesis. Phytochemistry 25, 2787-2789.

Lieutier, F.; Brignolas, F.; Sauvard, D.; Yart, A.; Galet, C.; Brunet, M.; van de Sype, H., 2003: Intraand inter-provenance variability in phloem phenols of Picea abies and relationship to a bark beetleassociated fungus. Tree Physiol. 23, 247-256.

McPherson, B. A.; Mori, S. R.; Wood, D. L.; Storer, A. J.; Svihra, P.; Kelly, N. M.; Standiford, R. B., 2005: Sudden oak death in California: Disease progression in oaks and tanoaks. For. Ecol. Manag. 213, 71-89.

McPherson, B. A.; Erbilgin, N.; Wood, D. L.; Svihra, P.; Storer, A. J.; Standiford, R. B., 2008: Attraction of ambrosia and bark beetles to coast live oaks infected by Phytophthora ramorum. Agric. For. Entomol. 10, 315-321.

McPherson, B. A.; Mori, S. R.; Wood, D. L.; Kelly, M.; Storer, A. J.; Svihra, P.; Standiford, R. B., 2010: Responses of oaks and tanoaks to the sudden oak death pathogen after $8 \mathrm{y}$ of monitoring in two coastal California forests. For. Ecol. Manag. 259, 2248-2255.

Ockels, F. S.; Eyles, A.; McPherson, B. A.; Wood, D. L.; Bonello, P., 2007: Phenolic chemistry of coast live oak response to Phytophthora ramorum infection. J. Chem. Ecol. 33, 1721-1732.

Parke, J. L.; Linderman, R. G.; Osterbauer, N. K.; Griesbach, J. A., 2004: Detection of Phytophthora ramorum blight in Oregon nurseries and completion of Koch's postulates on Pieris, Rhododendron, Viburnum and Camellia. Plant Dis. 88, 87.

Rizzo, D. M.; Garbelotto, M., 2003: Sudden oak death: endangering California and Oregon forest ecosystems. Front. Ecol. Environ. 1, 197-204.

Rizzo, D. M.; Garbelotto, M.; Davidson, J. M.; Slaughter, G. W.; Koike, S. T., 2002: Phytophthora ramorum as the cause of extensive mortality of Quercus spp. and Lithocarpus densiflorus in California. Plant Dis. 86, 205-214.

Rizzo, D. M.; Garbelotto, M.; Hansen, E. A., 2005: Phytophthora ramorum: integrative research and management of an emerging pathogen in California and Oregon forests. Annu. Rev. Phytopathol. 43, 309-335.

Ruuhola, T.; Salminen, J. P.; Haviola, S.; Yang, S. Y.; Rantala, M. J., 2007: Immunological memory of mountain birches: effects of phenolics on performance of the autumnal moth depend on herbivory history of trees. J. Chem. Ecol. 33, 1160-1176.

Salminen, J. P.; Roslin, T.; Karonen, M.; Sinkkonen, J.; Pihlaja, K.; Pulkkinen, P., 2004: Seasonal variation in the content of hydrolyzable tannins, flavonoid glycosides, and proanthocyanidins in oak leaves. J. Chem. Ecol. 30, 1693-1711.

Schultz, T. P.; Nicholas, D. D., 2000: Naturally durable heartwood: evidence for a proposed dual defensive function of the extractives. Phytochemistry 54, 47-52.

Slininger, P. J.; Burkhead, K. D.; Schisler, D. A., 2004: Antifungal and sprout regulatory bioactivities of phenylacetic acid, indole-3-acetic acid, and tyrosol isolated from the potato dry rot suppressive bacterium Enterobacter cloacae S11:T:07. J. Ind. Microbiol. Biotechnol. 31, 517-524. 
Venalainen, M.; Harju, A. M.; Kainulainen, P.; Viitanen, H.; Nikulainen, H., 2003: Variation in the decay resistance and its relationship with other wood characteristics in old Scots pines. Ann. For. Sci. 60, 409-417.

Wallis, C. M.; Eyles, A.; Chorbadjian, R.; McSpadden-Gardner, B. B.; Hansen, R.; Cipollini, D. F.; Herms, D. A.; Bonello, P., 2008: Systemic induction of phloem secondary metabolism and its relationship to resistance to a canker pathogen in Austrian pine. New Phytol. 177, 767-778.

Witzell, J.; Martin, J. A., 2008: Phenolic metabolites in the resistance of northern forest trees to pathogens - past experiences and future prospects. Can. J. For. Res. 38, 2711-2727.

Yarnes, C. T.; Boecklen, W. J.; Tuominen, K.; Salminen, J. P., 2008: Hybridization affects seasonal variation of phytochemical phenotypes in an oak hybrid complex (Quercus gambelii $\mathrm{x}$ Quercus grisea). Int. J. Plant Sci. 169, 567-578.

Zhou, L. G.; Li, D.; Jiang, W. B.; Qin, Z. Z.; Zhao, S.; Qiu, M. H.; Wu, J. Y., 2007: Two ellagic acid glycosides from Gleditsia sinensis Lam. with antifungal activity on Magnaporthe grisea. Nat. Prod. Res. 21, 303-309. 